\title{
5. HRECs and journalism research: The uneven playing field
}

\section{ABSTRACI}

This article continues an ongoing investigation into the problems that contemporary researchers in Australia using journalism as a methodology face in meeting the bureaucratic requirements of Human Research Ethics Committees (HRECs). This discussion in the peer-reviewed literature includes Richards (2009), Turner (2011), Lindgren and Phillips (2011), Romano (2012) and two articles by the author (Davies 2011a, 2011b). These two articles explored the flexibility built into the HREC's guiding document, the National Statement on Ethical Conduct in Human Research, in 2007 in order to make it possible for research that does not fit the standard scientific model to gain timely approval. The professional discussion has also included public conversations at the Journalism Education Association of Australia (JEAA) annual conferences and on the organisation's online discussion list. It is evident from these discussions that some researchers find the ethics application process sufficiently arduous that research using journalism as a methodology is effectively not possible for them. Meanwhile, others find the approval process to be painless and beneficial to their work. This raises the question of whether these differences are due to the researchers' competence in lodging applications for approvals, or differences in the approach taken by the various university-based HRECs. The novel contribution of this article to the discussion is quantitative data illustrating the diversity of approaches taken by HRECs to applications regarding research using journalism as a methodology and reflection on the implications for investigative journalism.

Keywords: ethics, journalism as research, investigative journalism, research methodologies, research journalism

KAYT DAVIES

Edith Cowan University, Perth 
7 HE WORD 'journalism' describes both a process and a product. Taken to mean the product produced by journalists it can be studied as an artefact by cultural studies scholars and others from various humanities and social sciences disciplines. Taken to mean a process, it is the collective noun for a group of practices and perspectives that are widely used to describe social and political events in a relatively rapid and readily transmitted and understood manner. As such, it is a methodology for researching and describing parts of the physical and socio-political world. While new technology and medium-shifts are changing the pragmatics of practising journalism, elements of the practice have long-standing histories (Lamble, 2004; Whittaker, Ramsey \& Smith, 2000). These time-honoured elements include information gathering, framing, and narrative practices, that are cited in numerous industry codes, text books and award guidelines as the defining features of best-practice and/or investigative journalism.

In recent decades journalism courses in Australian universities have flourished, and there are now hundreds of journalists working in the tertiary education sector, either full or part time. At the same time, the capacity of commercial newsrooms to fund investigative journalism has diminished, due to falling advertising revenues. This has raised the question about the extent to which investigative journalism can be conducted by journalists in the tertiary sector, and, if it is, whether it should be deemed to be 'research' and subject to the approval regime of Australian Human Research Ethics Committees (HRECs) (Richards, 2009; Davies 2011a, 2011b; Von Dietze, 2012). In addition to the Fourth Estate benefits of encouraging academics to do more bestpractice journalism, the upside of considering researching conducted using the process (methodology) of journalism to be research (as opposed to 'just' professional practice) is that it brings it within the scope of the Excellence in Research Australia (ERA) framework. ERA is a system for evaluating the quality of research undertaken in Australian universities against national and international benchmarks. It ostensibly aims to 'promote excellence', but it may also have funding implications (Knight, 2011, p.32).

Turner (2011) and Knight (2011) discussed the implications of the ERA on university funding and the reasons why journalism, as an academic discipline, stands to benefit from an increase in its 'research outputs', and to suffer if it fails to do so. Despite the inclusion of journalism work as acceptable nontraditional research outputs in the ERA since 2011, Nash (2013, p.125) pointed 
out that while Turner (2011) had been clear about the inclusion of journalism in the ERA, and professional practice had been successfully submitted to, and recognised by, the 2012 ERA round, there was still some contention around acknowledgement of journalism as a distinct field of academic research. $\mathrm{He}$ argued that 'in order to qualify as research practice any piece of journalism should be able to locate itself through an exegesis with respect to a defensible position' about its assumptions about the importance of reporting on the 'real', in the 'present' for particular 'publics'.

Nash (2103) restates that there is a lack of clarity and agreement about the point at which normal journalism crosses a threshold and becomes an academic activity. This is because journalism (as a product) ranges from being trivial and unoriginal through to being thorough and revelatory. However, the distinction of whether a journalism project ends up being published in a peer reviewed or non-peer reviewed publication cannot be used as the defining characteristic between normal journalism and academic research journalism. This is because HRECs are involved in assessing the research process, which is not retrospectively determined by publication destination. While peer reviewed publication is the goal of almost all research approved by HRECs, failure to attain publication does not undo a definition of the work as research. Ruling out publication destination as a defining characteristic leaves a grey zone between run-of-the-mill journalism and best practice, academic investigative journalism. This grey zone enables the existence of a range of opinions and perspectives about the eligibility and relevance of journalism research projects to the usual approval processes that academic research is subject to.

HRECs are constituted within Australian universities and other research institutions in accordance with guidelines provided by the National Health and Medical Research Council (NHMRC), through its Australian Health Ethics Committee (AHEC). The NHMRC Act (Commonwealth, 1992) gives the NHMRC responsibility for developing ethical guidelines for human research, and these guidelines, (published as the National Statement on Ethical Conduct in Research involving Humans, 2007), are widely accepted as the national standard. This document is the subject of a rolling review with amendments being incorporated 'as needed'. Its most recent update was published in December 2013, but did not include amendments to any clauses relevant to non-laboratory research (NHMRC, 2014). While adoption and adherence to National Statement is voluntary for institutions, an added incentive is that, on a project basis, the NHMRC and the Australian Research Council only fund 
research involving human subjects that has the approval of a HREC (NHMRC, 2013a). The upshot is that all Australian universities have HRECs and state that they require all university-based researchers to gain approval for research projects that involve humans as research subjects.

A number of recent papers and conference presentations have explored the nexus of journalism practice and ethics approvals. These include Richards (2009) who argued that 'HRECS work, and work well' and that informed dialogue is required between HRECs and 'those who conduct research in the emerging discipline of journalism' adding 'Whether they like it or not, the latter group has little choice but to engage in such a dialogue'. The author, (Davies 2011a; 2011b) discussed the scope of the flexibility offered within the bounds of the National Statement and quoted Professor Colin Thomson, one of the members of the NHMRC/ARC/UA working party that drafted the 2007 revision of the National Statement, observing that over recent years HRECs have been becoming increasingly risk averse and mechanistic in their response to applications.

Stressing that he was expressing his own opinion and not the committee's view, he said: "It's become about ticking the boxes and saying "no" if possible, not looking at ways that the researcher can proceed and being creative about how the intentions of the National Statement can be met while still allowing the project to go ahead.' (Davies, 2011b, p. 165)

This article also discussed the history and implications of section 4.6.1 of the National Statement that, according to Professor Thomson, was included specifically to allow 'Fourth Estate' research that holds power to account to go ahead unhindered by protocols designed to protect vulnerable people. However, it has not been previously known whether the protections this section of the National Statement offers are being evoked by journalism researchers and accepted by HRECs. This research is designed to fill this gap, and to gauge how many applications are gaining approval and under what conditions.

While anecdotal feedback received by the author over the past few years has confirmed Thomson's claim that there is considerable variation in how HRECs interpret of the intent of the National Statement, and consequently how many conditions they impose on researchers using journalism as a methodology, this variation has yet to be empirically documented. 
If such variation exists, journalism scholars based in different universities are operating under different regulatory regimes. For example some may be required to obtain hard copy signatures from every interviewee, and to submit their questions to their committees prior to every interview, while others are fast tracked through the system with little or no oversight. In order for progress to be made towards leveling the playing field, this study sought to document the variation in approaches currently being taken by Australian university HRECs to approving applications for research using investigative journalism as a methodology.

\section{Methodology}

\section{Questionaire}

In order to assess the degree of disparity in the approaches to 'journalism as research' currently being taken by Australian university HRECs a questionnaire project was undertaken.

It sought responses from all university-based HRECs to a set of questions. An online survey instrument called Qualtrics was used and the list of questions was kept deliberately short to reduce the extent to which time constraints were barriers to participation. The questions asked are listed below in the results section, along with the answers given.

Aptly illustrating the kinds of delays that HRECs can impose, that could delay the progress of a journalism research project and diminish its timeliness/ newsworthiness and its chances of achieving dissemination or co-publication via main stream media, the HREC committee responsible for approving this study rejected the initial ethics application on the grounds that I had not articulated how I would find the phone numbers for the ethics committees on the NHMRC list. My second application explained that I would use the internet to find the numbers on the relevant university websites and the project was then approved.

\section{Participants}

A list of Australian university-based HRECs was created using the NHMRC (2013b) list of all registered HRECs. I culled from the NHMRC list the HRECs based in hospitals and other non-university settings and, in cases where universities had more than one, the HRECs dedicated to medical research only were culled, leaving those universities represented by their social-science focussed HRECs. The result was a list of 39, their direct contact details were 


\section{INVESTIGATIVE JOURNALISM TRENDS}

then found via their websites or through phone calls to their universities.

Each HREC was then telephoned and invited to participate. Those that agreed were sent an email containing a letter of information about the project and a link to the survey. Completion of the survey was deemed by my HREC to be equivalent to signed consent for the data in the survey to be used.

During the phone conversations I explained that the questionnaires could be completed by committee members or chairs or by administrators, as long as the person completing it gave their name and their university so that I could eliminate repetition should two people from one university both respond. This only occurred in one instance and as the two committee members' answers were the same they were counted as a single answer. Administrators were deemed to be qualified to respond as the questions were about university policies and past decisions that they were likely to be as competent to speak about as committee members.

The process of phoning the HRECs and sending out the surveys took place in three bouts, one in late October 2012, one in late November 2012 and one in late January 2013. Of the 39 HRECs telephoned a satisfactory 61 percent response rate was attained measured by completed questionnaires and 72 percent, if the emailed responses and incomplete questionnaires are counted.

\section{Results}

The results indicate that there is considerable variation in the approaches of different HRECs to journalism as research. While their responses to some questions were close to unanimous, to others they were split as decisively as 50:50. The following section plots their responses and summarises comments sent by email and left in the other and comments sections of the questionnaire. Please note that not every participant answered every question. Where comments sent by email or left at the general comments section at the end of the questionnaire referred to the number or topic of a specific question those responses are listed under the question. Other responses are listed at the end. Comments have been edited to correct typos, for de-identification and for brevity.

\section{Question 1}

Do you have a specific policy or guidelines about how journalism (or research using journalism as a methodology) is ethically assessed by your university, or does it go through the same processes as all other humanities research? 
INVESTIGATIVE JOURNALISM TRENDS

\section{Table 1: Journalism guidelines}

\begin{tabular}{|l|c|c|}
\hline Answers & $\mathrm{n}=28$ & $\%$ \\
\hline Yes, we have specific guidelines or policies that mention journalism & 2 & 7 \\
\hline No, we have no specific guidelines of policies that mention journalism & 26 & 93 \\
\hline
\end{tabular}

Responses to Question 1

Comments:

- Yes, we have HREC Committee Guidelines.

- Yes, but our guidelines are currently draft.

- No, but this may change in the future ... to date our ethical review bodies have not been asked to review 'journalism' as a separate research method.

Five other participants left comments explaining that their HRECs have no discipline-specific guidelines or policies, for any discipline or field.

\section{Question 2}

Do you require all journalism (or research using journalism as a methodology) to be assessed by your HREC, if it is done by your university's a) staff; b) postgraduates; c) undergraduates?

\begin{tabular}{|l|c|c|}
\hline Table 2: Assessment by HREC & $\mathrm{n}=24$ & $\%$ \\
\hline Answers & 15 & 63 \\
\hline Undergraduate students & 23 & 96 \\
\hline Postgraduate students & 24 & 100 \\
\hline Staff &
\end{tabular}

Responses to Question 2

The comments illustrated a range of rationales and contemplation of the threshold for the definition of journalism as research:

- All researchers fill out a risk assessment and all low level risk is handled at the school level, high level goes to the HREC. Undergrad journalism for assessment purposes only doesn't tend to come through, and post grad and staff work only does if it is high risk.

- Undergrad research only requires ethics approval if its purpose is not just for teaching and learning, or it will be published, or the participant group is vulnerable, or participants can be identified and may find that problematic, or if information obtained is recorded in a way that disclosure of responses outside the research team could 
reasonably place the participants at risk of criminal or civil liability or be damaging to the participants' standing, employability or reputation, or is assessed as greater than low risk.

- If research by academics or students falls within the definition of 'human research' outlined in the National Statement (p. 8), it would be subject to ethical review at the appropriate level. I would add that some research outputs would also be involved, such as publication in a journal or at a conference or research training in the case of a student.

- We tend to view undergraduate work for course credit as not requiring ethics clearance as this is training in method, not research.

- In the HREC context - is journalism research? Undergrads rarely, if ever, do research, if it is and it uses human subjects then, yes, it needs HREC approval. If the definition you use is an intention to publish then it shouldn't matter if the work is peer-reviewed or not. More often the definition comes down to academic credentialing, is it going to be used for academic credit, promotions or grant applications? If it is then we do need to treat it as research. We understand that journalism is different to other fields and encourage lots of conversations with our committee.

- We do not consider journalism per se as a research activity. As such I have answered the questions with only journalism undertaken for research purposes in mind-i.e. not all journalism.

- Staff doing journalism would not typically need ethics approval, as this would normally be a form of professional practice. It is not at all clear that Journalism is a discrete research methodology: it is an aggregation of many methods, from statistical analysis, through interview and literature survey to ethno-methodology etc.

\section{Question 3}

Does your committee consider journalism (or research using journalism as a methodology) to be 'low risk' and therefore able to be processed using a fast track, or exemption process?

Comments indicating likely referral to a low risk assessment process:

- Low Risk Sub-committee and considered on case by case basis.

- Although it does depend on how contentious the comments are.

- It would probably be low risk but we rarely receive journalism projects to consider. 
INVESTIGATIVE JOURNALISM TRENDS

Table 3: 'Low risk' criteria

\begin{tabular}{|l|c|c|}
\hline Answers & $\mathrm{n}=26$ & $\%$ \\
\hline Yes, please explain your rationale and process & 11 & 42 \\
\hline No & 15 & 58 \\
\hline
\end{tabular}

Responses to Question 3

An additional 13 comments indicate no default referral of journalism projects to a low risk assessment process and explained that each case is considered based on assessment of the risk involved:

- Two comments mentioned that there is an expedited process for low risk projects.

- Only one mentioned consideration of potential benefits

- Two mentioned that interviews can be damaging and that journalism projects can be high risk

This is a typical response:

- Dependent upon the subject matter, participant groups, and whether consent is obtained from participants - in other words, it needs to meet the definition of Low Risk, and not involve the participant groups specified in the National Statement.

This comment adds the element of the HREC's familiarity with the researcher:

- Even interviews can be very damaging, so we would have to apply a risk matrix to give context. We also get more familiar with and trusting of individual researchers.

This comment adds the detail that HRECs are primarily predisposed to consider the rights of individuals:

- An essential value in the research ethics approval process is respect for persons. The journalism research methodology appears, at least in some of the way it is being promoted, to want to do away with this value. HREC needs to be satisfied that if this methodology is used that it adheres to the requirement to respect persons. This will include as far as possible gaining voluntary, informed consent from participants before conducting the research. The nature of the research methodology does not mean that it is always to be considered more than low risk. Each research project needs to be assessed on its merits. 
INVESTIGATIVE JOURNALISM TRENDS

\section{Question 4}

Has your HREC ever allowed a researcher using journalism as a methodology an exemption from the requirement of consent on the grounds explained in section 4 of the National Statement, to do with public interest at times overriding the ethical good of individual consent?

\begin{tabular}{|c|c|c|}
\hline Answers & $n=24$ & $\%$ \\
\hline No & 9 & 32 \\
\hline Not to my knowledge & 18 & 64 \\
\hline Yes, can we have details? & 2 & 7 \\
\hline
\end{tabular}

Responses to Question 4

These two comments indicate a lack of familiarity with the wording of section 4.6 of the National Statement:

- 'public good' is not an exemption clause within the National Statement - although the NS does allow for exemptions, rather the question is of whether the activity is 'research' and if so, the level of associated risk to the individual.

- The fourth question refers to Section 4 of the National Statement ... It is not clear which point from Section 4 the survey refers to. These two comments explain how HRECs have used the flexibility possible within the National Statement to enable research in which the requirement of informed consent in waived. It is worth noting that Chapter 2.3 of the National Statement (2007, p. 24) entitled Qualifying or waiving Conditions of Consent links (at point 2.3.7) to section 4.6.1 for further clarification on waiving consent in cases where 'the value of exposing illegal activity justifies the adverse effects on the people exposed':

- If there is to be approval for a consent waiver, this would accord with National Statement Chapter 2.3 ... Part of the rationale here would be the public interest dimension, as HRECs are required to have minimum non-institutional/lay/non-researcher membership. (Indeed I have had experience of concern being expressed by an interested party in relation to a consent waiver approved at HREC level; responding to the concern was helped by the care taken with the review and the broader membership present.)

- Our HREC has allowed projects that do not seek consent; we have 
allowed projects that involve deception; we have applied the $\mathrm{Na}$ tional Statement in all decisions. We would always be open to argument that specific consent by participants should not be sought, consistent with NS 2.3.

\section{Question 5}

Have you ever used the flexibility the National Statement permits to tailor the usual approval process to facilitate the use of journalism as a methodology by:

a. allowing consent to be sought and granted following interviews rather than before interviews?

b. allowing consent to be assumed (rather than proved through signing a document), if the purpose of the interview is explained and the interviewee then participates in the interview (in person or by phone)?

c. allowing consent to be assumed, if the purpose of the interview is explained and the interviewee then responds by email or by completing and sending back a questionnaire?

\section{Graph 1: National Statement flexibility}

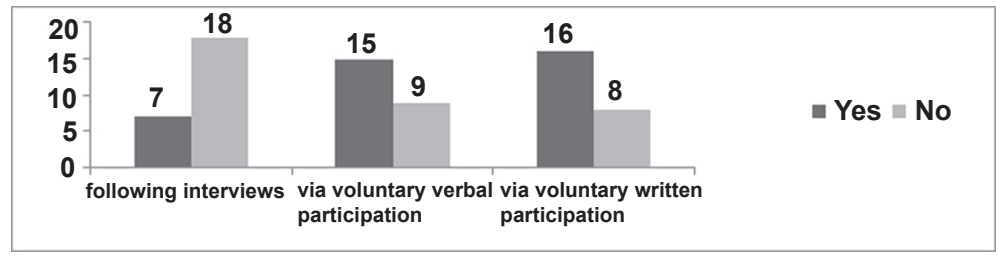

Responses to Question 5

Comments:

These comments explained why these variations are allowed and the additional conditions applied:

- We can, and have, allowed consent to be confirmed orally, or assumed and confirmed later by email — but not as a blanket, only in the context of an individual project when the standard process cannot be applied.

- We consider verbal consent and implied consent as (active) voluntary informed consent mechanisms (as per the National Statement), 
so would not consider these as only 'assumed' consent (which to me only implies passive consent). Depending on the risks of the research, we may ask researchers proposing to use non-written consent mechanisms to justify their use, in consideration of the possible risks of not gaining written consent.

- Re b) \&c): We would allow implied consent in certain cases around non-identifiable data collected.

- $\quad \operatorname{Re}$ b): This would only be permitted where the interviews were recorded, and the participant is asked for consent, and the verbal response is recorded.

- We would require that before any research/interview took place that the participant was fully informed as to the nature of the research and what the intended use of the data collected via the interview would be. Informed consent can be informal and does not necessarily need to be written. A recorded explanation of the research and verbal consent is acceptable.

- We allow the use of implied consent, but this is stated on information sheets - e.g. by submitting this survey you are consenting to its use in our study.

These comments specifically discuss approval following rather than prior to interviews:

- Re a): The committee has discussion about this on its agenda, but we haven't done it yet.

- We have allowed researchers to seek consent from people to use information gathered without prior ethics consent (we do not allow retrospective approval of data gathering, but if each person who has provided information gives specific and informed consent to use data previously gathered then we can give ethics clearance). This is not easily gained, but has been done in certain specific situations.

- In some cases we have allowed interview transcripts to be approved retrospectively when a follow up interview is not possible for some reason. This has involved a tailored information letter to get the transcript confirmed, but more often we encourage journalism researchers to conduct a scoping visit, then apply for the ethics approval and then return to the participant to formally conduct the interview.

- We also acknowledge that journalism is 'opportunistic' and there- 
fore under extenuating circumstances have allowed journalism researchers to seize an opportunity to conduct an interview prior to formal approval. Only if the research is, without question, low risk and only when the researcher follows standard ethical practices of informed consent. However, this is only considered under extenuating circumstances and is rare. The responsibility lies with the researcher to demonstrate that there was no possibility that the circumstances were foreseeable and ethics approval could have been sought prior to the interview.

\section{Additional comments}

- This area is probably one that 'flies under the radar' to an extent. I suppose there is a possibility that we should be seeing more ethics applications from this area.

- In case I might have given you quite the wrong impression from my answers; believe it or not the ethical review bodies I serve do not ordinarily take too conservative or too risk-averse an approach, ... Members on the ethical review bodies take seriously their obligation to review carefully the proposals submitted. The issue is usually to do with badly prepared or incomplete ethics clearance applications which are sent back for revision, to clarify detail or to identify and address the relevant issues. Hardly any human research proposal is rejected; my experience has been that a rare rejection occurs where no respect can be seen to be accorded the participant or where the risk to the participant cannot be justified even by the anticipated outcome or benefit (eg, a recorded answer by an identifiable individual to a question would cause grave harm or worse). The rationale is usually communicated to the researcher. The devil really is in the detail put forward for review, or lack thereof.

\section{Discussion}

As stated at the outset, the data presented here offers scope for much discussion and analysis and a full exploration of it is beyond the scope of a single paper. This section will however begin the process of contextualising it. The responses to question one indicate that while most HRECs have no specific guidelines referring to journalism at least two that responded do, (their policies are available from the author on request). In addition to these, 
the University of Technology Sydney (which did not respond) makes this point on its website (2013): 'Note: Some activities, such as investigative journalism, will involve interviewing people and collecting information but are not "research" as such. Activities such as these may be more readily dealt with through the appropriate professional codes and guidelines (e.g. the MEAA Code of Ethics)'. This indicates that at least three HRECs have specifically acknowledged the need for clarity about what ethics approval work is expected to be done (and for what kind of projects) by journalism staff and students who are scouring archival data, conducting interviews and writing articles for publication and, in some cases, for inclusion in ERA tallies.

Professor Thomson pointed out in Davies (2011a) that while publication in a peer-reviewed journal, as opposed to a non-peer reviewed magazine or newspaper, is sometimes taken as a de-facto means of distinguishing academic research from other writing, whether and where the work is published is not a valid way of determining whether a project is, or is not, a research project. Confusion about when journalism is, or is not, research, emerged as a theme in the written responses to question two. The National Statement (2007, pp. 7-8) definition of research starts by admitting that there is no generally agreed definition and ends with a list that includes human beings taking part in interviews and that 'data' being made available through publication. Given that many undergraduate journalism programmes produce prolific publications and encourage students to interview people, write and create broadcast articles and compile online portfolios of their work, it is interesting to note that almost two thirds of the 22 HRECs that answered question two are under the impression, or inclined to state, that all undergraduate journalism projects are submitted for approval (with no distinction between different types of journalism). As most undergraduate programmes require all students to write several articles a year, this may indicate a failure of internal communication mechanisms within universities. This sceptical notion is supported by the comment by one participant that journalism research may 'fly under the radar' to an extent.

Question three tested for agreement about whether journalism is, or is not, usually considered to be low risk and subjected to a faster-than-usual approval process. The result was a fairly even split (10 yes/15 no) with many of the comments adding that each project is also considered on a case-by-case basis, with potential for referral to the full committee. This indicates a level of (but not complete) agreement with the notion that consenting adults can speak to 
journalists without subjecting themselves to undue harm. Other comments added that interviews can be damaging and that participant vulnerability needs to be considered. On this point, reflection by journalist Alex Soares (2011, also cited in Von Dietze, 2012) on the process of gaining HREC approval for an honours project using journalism as a methodology is relevant. Soares observed that the four-month long process of negotiation and gaining HREC approval resulted in his project shifting from being journalism, to being an oral history project. He observed that 'sometimes compliance with the ethical guidelines was made impossible by the logistics in the field' (p. 47) and he raised the issue of paternalism, first flagged by Edwards et al (2004), and wrote 'for me to have assumed in this instance that my interviewees would not be capable of judging for themselves the legitimacy of the risks they faced, having been fully informed of those risks, would in my view have itself been unethical" (Soares, p. 48). While poor quality journalism, that breaches the industry's own codes of conduct, can be exploitative and damaging to participants, high quality journalism is fair, balanced, accurate and respectful of the rights of both interviewees and the citizenry. While Von Dietze (2012) suggests that an HREC committee can function as a sounding board for journalists to ensure that participants are not placed at undue risk, in Soares' case it came at the cost of months of time and considerable effort that could have otherwise been devoted to more productive aspects of the research. While Von Dietze advocates for a consultative approach that involves a committee learning to trust individual researchers, UTS's default requirement that all journalism must be compliant with industry codes (such as the MEAA Code, 2013; the Australian Press Council Principles, 2013; or the ABC Code of Practice, 2013) may be a more time-efficient way of ensuring that the same standards are met.

While Davies (2011a) explored the history of chapters 2.3 and 4.6.1 of the National Statement (2007) that allow for the requirement of informed consent to be waived in cases where the public good is better served by publication without consent, the responses to question four indicate that these clauses are rarely used. This means that most of the journalism that has been assessed and approved by HRECs has been the sort that involves compliant interviewees, happy to have their comments published. Although this kind of journalism is undoubtedly valuable, for journalism to function as the Fourth Estate, it needs to be prepared to hold power to account by asking powerful and sometimes resistant interviewees questions that they would rather not answer, on behalf 
of the public, who lack access to these people (Schultz, 1998, pp. 51-54). Further research could investigate why these clauses have not been more widely used by journalism academics and whether only a certain kind of tame and agreeable journalism is deemed to be possible in HREC contexts.

The preamble to the National Statement (p. 4) states that the 2007 revision 'provided greater flexibility in the practice of ethical review, depending on the type and area of research and the degree of risk involved'. It emphasises that the National Statement is a guideline and that individual researchers and institutions hold primary responsibility for ensuring their research is ethically acceptable. Question five asked whether the flexibility the National Statement permits is used to allow research to be spontaneous, opportunistic and free of the sometimes-intimidating formalities of signing documents. The responses again indicated a wide array of HREC practices, with some rigidly requiring prior approval and a signature from every interviewee and others allowing some or all of these flexible options. The comments indicated a range of conditions such as 'only with non-identifiable data' or 'only where consent is recorded' and most stated that a rationale would be required from the researcher. The comments justifying why flexibility was allowed indicated that some HRECs are more committed than others to facilitating research using a wide array of methodologies.

While several comments made the point that it is the responsibility of the researchers to justify why usual processes should not be applied, only one openly stated that refusals were often based on 'badly prepared or incomplete' ethics applications. These comments indicate that, in addition to the now demonstrated variation in HREC approaches, that HRECs also observe a variation in the quality of applications that they receive from journalism researchers.

\section{Conclusion}

In summary, if universities are keen to increase research productivity and HREC compliance of their journalism academics, they could do any or all of these four things: Firstly, they could provide clearer guidelines about what kinds of journalism undertaken by undergraduates, post-graduates and staff fall under the remit of HRECs, as this study has documented a fact alluded to in many other papers, that there is confusion about this. Secondly, they can encourage HRECs and journalism academics to engage openly and consultatively with each other. Thirdly, they could consider whether simply requiring 
that journalism research be compliant with specific industry codes would expedite ethics approval processes and enable more research activity. And finally, they could consider encouraging their HRECs to follow the lead of the more flexible and accommodating committees that participated in this study.

In addition, if journalism academics are interested in taking Turner's (2011) advice and increasing research outputs then two compatible approaches can be taken. One involves continuing the work commenced by Romano (2012) that seeks to improve the ethics-negotiation skills of individual journalism academics. The other, is a discipline-driven attempt to promote a unified best-practice way for HRECs to respond to applications involving journalism as a research methodology. It was the suggestion of the late former president of the JEAA, Anne Dunn (2012), that: 'We could roll this issue into the Discipline Standards Network that JEAA and ANZCA are developing with an ALTC/DEEWR grant ... [as] It does seem to raise questions closely related to the larger one of how best to continue the integration of journalism practice and journalism studies into the humanities and social sciences in Australian universities.'

\section{References}

ABC (2013). Our editorial policies. Retrieved on March 8, 2013 from http://about. abc.net.au/how-the-abc-is-run/what-guides-us/our-editorial-policies/

Australian Press Council (2013). Statements of principles. Retrieved on March 8, 2013 www.presscouncil.org.au/statements-of-principles/

Davies, K. (2011a). Journalism as research within the framework of academic ethics. Australian Journal of Applied and Professional Ethics, 12 (1), 70-79.

Davies, K. (2011b). Journalism and HRECS: From square pegs to squeaky wheels. Pacific Journalism Review, 17 (1), 157-174.

Dunn, A. (2012, April 15).Re: UC FOI story in Crikey. JEAnet [email discussion list]. Archived by University of Wollongong. Reference http://mailinglists.uow. edu.au/mailman/listinfo/jeanet

Edwards, S., Ashcroft, R., \& Kirchin, S. (2004). Research ethics committees: Differences and moral judgement. Bioethics 18 (5), 409-427.

Knight, A. (2011). A new ERA for journalism educators. Australian Journalism Review, 33 (1), 29-34.

Lamble, S. (2004). Documenting the methodology of journalism. Australian. Journalism Review, 26 (1), 85-106.

Lindgren, M. \& Phillips, G. (2011). Conceptualizing journalism as research: Two paradigms. Australian Journalism Review, 33 (1), 5-7.

MEAA (2013). Media, Entertainment and Arts Alliance: Code of Ethics. Retrieved on March 8, 2013 from www.alliance.org.au/code-of-ethics.html 
Nash, C. (2013). Journalism as a research discipline. Pacific Journalism Review, 19(2), 123-135.

National Health and Medical Research Council, Australian Research Council \& Australian Vice-Chancellors' Committee (2007). National statement on ethical conduct in research involving humans. Canberra: Commonwealth of Australia.

NHMRC (2013a). Research ethics committee and regulatory approvals clearance. Retrieved on June 19, 2013 from www.nhmrc.gov.au/grants/policy/research-ethicscommittee-and-regulatory-approvals-clearance

NHMRC (2013b). Human Research Ethics Committees. Retrieved on March 8, 2013, from www.nhmrc.gov.au/health-ethics/human-research-ethics-committees-hrecs/ human-research-ethics-committees-hrecs

NHMRC (2014). National Statement on Ethical Conduct in Human Research (2007) Updated December 2013. Retrieved on March 3, 2014 from www.nhmrc.gov.au/ guidelines/publications/e72

Richards, R. (2009). Uneasy bedfellows: Ethics committees and journalism research. Australian Journalism Review, 31 (2), 35-46.

Romano, A. (2012). Ethics clearance made easy. Paper presented at Journalism Educators Association of Australia (JEAA) Conference, Melbourne, Australia, December 2, 2012.

Schultz, J. (1998). Reviving the fourth estate: Democracy, accountability and the media. Melbourne: Cambridge University Press.

Soares, A.W. (2011). A sojourn in journalism: Building trust, meeting challenges. Unpublished honours thesis. Murdoch University, Australia. February 2011.

Turner, G. (2011). The ERA and journalism research. Australian Journalism Review, 33 (1), 5-7.

University of Technology Sydney (2013). Ethical Conduct of Research-Academic and Support Staff Policy. Retrieved on March 8, 2013 from www.gsu.uts.edu.au/ policies/researchethicpol.html

Von Dietze, E. (2012). A story behind the story: Journalism, research and ethics. Paper presented at Australasian Ethics Network Conference, Brisbane, Australia. 16 February, 2012.

Whittaker, W., Ramsey, J. \& Smith, R. (2000). Media writing: Print, broadcast and public relations. Longman: New York.

Dr Kayt Davies is a senior lecturer in journalism at Edith Cowan University, Perth, Western Australia, and is editor of the online journal Research Journalism. ro.ecu.edu.au/research_journalism/

k.davies@ecu.edu.au 